\title{
Removing barriers to rehabilitation: Theory-based family intervention in community settings after brain injury
}

\author{
Taryn M. Stejskal \\ Wellness Strategies, P.C., 8395 Keystone Crossing, Suite 306, Indianapolis, IN 46240, USA \\ Tel.: +1 317257 7544; Fax: +1 317257 7443; E-mail: thinktaryn@gmail.com
}

\begin{abstract}
Rehabilitation professionals have become increasingly aware that family members play a critical role in the recovery process of individuals after brain injury. In addition, researchers have begun to identify a relationship between family member caregivers' well-being and survivors' outcomes. The idea of a continuum of care or following survivors from inpatient care to community reintegration has become an important model of treatment across many hospital and community-based settings. In concert with the continuum of care, present research literature indicates that family intervention may be a key component to successful rehabilitation after brain injury. Yet, clinicians interacting with family members and survivors often feel confounded about how exactly to intervene with the broader family system beyond the individual survivor. Drawing on the systemic nature of the field of Marriage and Family Therapy (MFT), this article provides information to assist clinicians in effectively intervening with families using theory-based interventions in community settings. First, a rationale for the utilization of systems-based, as opposed to individual-based, therapies will be uncovered. Second, historically relevant publications focusing on family psychotherapy and intervention after brain injury are reviewed and their implications discussed. Recommendations for the utilization of systemic theory-based principles and strategies, specifically Cognitive Behavioral Therapy (CBT), Narrative Therapy (NT), and SolutionFocused Therapy (SFT) will be examined. Descriptions of common challenges families and couples face will be presented along with case examples to illustrate how these theoretical frameworks might be applied to these special concerns postinjury. Finally, the article concludes with an overview of the ideas presented in this manuscript to assist practitioners and systems of care in community-based settings to more effectively intervene with the family system as a whole after brain injury.
\end{abstract}

Keywords: Brain injury, caregivers, family therapy, intervention

\section{Introduction}

Traumatic Brain Injury (TBI) is a pernicious agent of long-term disability in the U.S., affecting every racial, ethnic, and cultural group as well as people of all ages, genders, socio-economic statuses, and religions [15]. In 2008, the Centers for Disease Control and Prevention (CDC) indicated that the annual incidence of TBI is 1.4 million and 3.17 million civilians live in the U.S. with TBI-related disabilities [40]. Moreover, TBI is marked by a wide array of resulting difficulties including significant cognitive [2,28,37], psychosocial [5,32, 35], behavioral, emotional, and physical [24] deficits that impact the injury survivor and their significant family relationships [18].
In addition, many U.S. service members in both Afghanistan and Iraq have been exposed to Improvised Explosive Devices (IED), resulting in a record number of soldiers returning home with TBIs [36]. In previous wars less than $20 \%$ of military casualties sustained brain injuries, but with medical advances, as many as $50 \%$ of soldiers are returning home with blast induced TBIs, adding to the cadre of injured survivors and their families in need of long-term therapy and support. Often injuries are a combination of mild TBI (mTBI) and symptoms of Post Traumatic Stress Disorder (PTSD) [30]. Given the exponential growth of soldiers with this "signature" injury, much has been made of how to care for the burgeoning population of injured service members and civilians identified by the 
CDC [40]. Consequently, TBI is often referred to as the "silent epidemic" [14] given the prolific nature of TBI coupled with the lack of public awareness and available federal funding. Comparatively, TBI still enjoys relatively little federal funding even though more people are permanently injured or die annually in the United States from TBIs than are diagnosed with breast cancer, multiple sclerosis, spinal cord injury, and HIV/AIDS combined $[22,33]$. Survivors of TBI and their spouses often receive minimal assistance after hospital discharge and physical rehabilitation have ceased. Therefore, family members are charged with caring for the survivor over the course of rehabilitation and community integration [16]. In fact, survivors' ability to access rehabilitative services postinjury is often predicated on the presence of willing family member caregiver.

TBI is a phenomenon that affects the survivor as well as the family as a whole. Yet, with the individuallybased focus of the medical model of treatment, and despite the family's pivotal role in rehabilitation, the survivor is often the only person who receives rehabilitative counseling, if at all. The survivor and family members embark on three distinct stages of rehabilitation that include: (1) acute care: the period of time the survivor remains in the hospital treatment setting; (2) chronic care: the period of time the survivor participates in outpatient rehabilitation services such as occupational therapy, physical therapy, speech therapy, etc.; and (3) maintenance of gains and long-term rehabilitation needs: the period of time the survivor and family is thought to rejoin the community, but is without formal rehabilitative services. While it should be noted that not all survivors and families engage in each stage, a large majority of families move through each stage at varying rates depending on the nature and severity of the injury. Yet, a common concern is that families and survivors alike often struggle with social support and chronic stress during the third stage of rehabilitation without the structure of formal treatment services. In order to better to meet the needs of families and survivors, this research article explores the utility of family psychotherapy in assisting families with long-term concerns and adjustment over the lifespan of the injury.

\section{Rationale for systems-based family psychotherapy and intervention}

Since Lezak's [23] ground breaking work over 30 years ago, clinicians and researchers alike agree that brain injury is a family affair wherein each person is impacted by the injury, often in different ways. In addition, recent research suggests that the family plays an extremely important role in survivors' rehabilitation, significantly affecting survivors' psychological adjustment to injury-related disability [38]. Furthermore, Testa and colleagues [38] found that distressed family functioning correlated strongly with increased rates of survivors' neurobehavioral symptoms. Therefore, the quality of the family interaction is actually related to the type of recovery the survivor is able to attain. Although the family system is markedly impacted by the injury, provides care for the survivor over time [9], and, in part, dictates the extent of rehabilitation, interventions and treatment have been typically focused solely on the survivor.

While individually based psychotherapies recognize the importance of the family relationships to an extent, the complimentary field of Marriage and Family Therapy (MFT) and family intervention has a number of distinct advantages over individual therapies [13]. First, the clinician's objectivity is increased by soliciting viewpoints from each family member, as opposed to only one individual. Second, participation of the entire family helps to foster a sense of mutual ownership of the problems, instead of an identified patient wherein only one person in the family is considered to be the problem. Third, family meetings allow for enactments, or opportunities for the family to play out typical patterns of interaction in the therapist's office. Rather than being told about a given interaction, the therapist is able to observe the interaction pattern firsthand and intervene in real time. Finally, families that change together stay together. This means that when the family structure and the relationships within the family system are transformed, so too is each individual constituent member, revolutionizing family interaction as a whole [29]. Moreover, family therapy exerts change on the whole family, and change is likely to be more lasting as family members make synchronous changes in concert.

\section{Publications focusing on family therapy after brain injury}

\subsection{Family psychotherapy}

In general, family therapy conducted postinjury should help the survivor and family members better understand the injury, assist family members in setting realistic expectations and adjust to the injury, and sup- 
port the system over the course of rehabilitation [26]. Family therapy often addresses pre-existing concerns such as, for example, previous losses, relationship cutoffs, breaches of trust, and communication issues. A brain injury is likely to reduce a family's emotional resources, exacerbating the problems that existed within the family preinjury. It is not uncommon for a family to visit a therapist's office with the brain injury as the presenting concern, and also focus on a previous "relationship injury" such as the absence of a parent or a previous infidelity. For many families, brain injury adds an additional layer of complexity atop the long-standing pre-existing relationship concerns. Good family therapy addresses both the injury as well as the family's previous relational concerns in tandem.

Family psychotherapy is generally comprised of sessions that include the family and survivor or subsystems within the family, with the goal of healing previous relationship concerns and providing support for the family's adjustment to brain injury [17]. In particular, Christensen and colleagues [4] provided six specific topics for clinicians' consideration when working with families postinjury. These topics include: (1) the process and meaning of recovery from injury; (2) effects on marital relationships; (3) role changes and loss of personal identity; (4) unmet family needs, especially emotional support needs; (5) predictors of family functioning; and (6) the Head Injury Family Interview (HI-FI), a tool for clinical intervention.

Webster and colleagues [39] emphasize the role of the rehabilitation team in supporting families postinjury and the unique considerations of practitioners in situations wherein family structure breaks down via separation or divorce. In particular, issues of fluctuating goals, related to changes in marital commitment, can create difficulty for clinicians supporting rehabilitation as practitioners may feel they are trying to hit a moving target in order to provide the appropriate level of support for the family. Also, individual family members may have vastly difference conceptions of the nature and cause of problems arising from the injury. In addition, family members may have specific and disparate individual needs. For example, the survivor may require assistance with regaining a sense of identity, while a sibling may need help with anger management, and parents may require grief and loss work related to the implications of the injury. In cases where a family may undergo structural changes due to separation and divorce, clinicians are also faced with special confidentiality considerations. The rehabilitation team as a whole, as well as individual clinicians, are charged with the task of carefully deciding how communicate with a fragmented family system and how to limit access to information to people who are no longer part of the clinical work [39].

Kreutzer and colleagues [19] outline typical pitfalls clinicians might encounter when working with families postinjury using case examples to underscore their points. These common pitfalls include attacking denial without accounting for family members' feelings of distress, vulnerability, and uncertainty as well as the utility of denial as a human coping skill to avoid being flooded with feelings of pain and loss. The authors also discuss the perils of providing inconsistent information to family members about the patient's prognosis, the propensity for clinicians to attribute all the difficulties to the injury without assessing for pre-existing sources of stress, navigating differential reports of behavior provided by the survivor versus other family members.

\subsection{Manualized and structured family interventions}

In the same vein as family therapy, manualized family interventions, despite individual patient differences, offer an opportunity for a structured approach to mitigate commonly encountered family problems postinjury. For a complete review of manualized interventions in the field of brain injury, see Kreutzer and colleagues [21]. One of the few evidence-based family interventions after brain injury, the Brain injury Family Intervention (BIFI) arose from clinical experience and a review of the relevant research literature [20]. The curriculum requires the survivor at least one family member to participate in a series of rehabilitation topics. The BIFI initially included 16 topics for intervention, and was later paired down to 11 critical topics for empirical validation [21]. In order to facilitate community support, treatment sessions are scheduled based on the family's availability, and on-going psychotherapy is offered after the structured BIFI sessions are complete.

Backhaus and colleagues [1] piloted a randomized waitlist control study of a Cognitive Behavioral Therapy (CBT) group intervention for survivors of brain injury and their caregivers. In order to teach necessary skills, such as communication and emotional control, to family members and survivors alike in a community setting, this empirically supported group provides 16 two-hour sessions to help people better understand brain injury and adjust to the limitations of the injury. In particular, the authors focused on cultivating the concept of perceived self-efficacy (PSE) during the BICS program, a especially helpful trait thought to assist peo- 
Table 1

Comparative review of family systems theoretical frameworks

\begin{tabular}{|c|c|c|c|c|}
\hline $\begin{array}{l}\text { Theoretical } \\
\text { model }\end{array}$ & Theoretical assumptions & Goals for therapy & $\begin{array}{l}\text { Conditions for behavior } \\
\text { change }\end{array}$ & Therapeutic techniques \\
\hline $\begin{array}{l}\text { Cognitive Be- } \\
\text { havioral Ther- } \\
\text { apy (CBT) }\end{array}$ & $\begin{array}{l}\text { Cognitions, behavior, and emo- } \\
\text { tions are a trifecta connected } \\
\text { in concert to create human in- } \\
\text { teractions and responses to the } \\
\text { environment; each facet is tied } \\
\text { to and influences aspects of } \\
\text { self, experience, and human } \\
\text { response }\end{array}$ & $\begin{array}{l}\text { Modifying specific patter- } \\
\text { ns of behavior, cognition, } \\
\text { and emotion that main- } \\
\text { tain the presenting symp- } \\
\text { tom; treatment is tailored } \\
\text { to the individual, couple, } \\
\text { and family needs }\end{array}$ & $\begin{array}{l}\text { Cognitions, behavior, and } \\
\text { emotional responses are } \\
\text { changed when contingen- } \\
\text { cies for reinforcement are } \\
\text { altered through specific } \\
\text { therapeutic techniques }\end{array}$ & $\begin{array}{l}\text { Psychoeducation or bibliother- } \\
\text { apy focused on a specific top- } \\
\text { ics related to treatment such } \\
\text { as depression or anxiety; emo- } \\
\text { tional support and empathy; } \\
\text { de-escalation of conflict; skill } \\
\text { building and training }\end{array}$ \\
\hline $\begin{array}{l}\text { Narrative } \\
\text { Therapy (NT) }\end{array}$ & $\begin{array}{l}\text { Personal experience is fun- } \\
\text { damentally ambiguous; there- } \\
\text { fore experience is socially con- } \\
\text { structed rather than objective- } \\
\text { ly true; as a means of organiz- } \\
\text { ing meaning, people tell them- } \\
\text { selves stories that shape their } \\
\text { behavior and experience }\end{array}$ & $\begin{array}{l}\text { Assist in rewriting problem } \\
\text { saturated stories (person- } \\
\text { al narratives with destruc- } \\
\text { tive assumptions), identify } \\
\text { unique outcomes, and cre- } \\
\text { ate more beneficial and in- } \\
\text { clusive viewpoints }\end{array}$ & $\begin{array}{l}\text { People are encouraged to } \\
\text { externalize problems, or } \\
\text { view the problems as out- } \\
\text { side themselves. Families } \\
\text { can join together against } \\
\text { the problem and create new } \\
\text { stories }\end{array}$ & $\begin{array}{l}\text { Externalization: The problem } \\
\text { is not intrinsic to the person, the } \\
\text { problem acts upon the person or } \\
\text { family; re-authoring the narra- } \\
\text { tive: People write new stories } \\
\text { to include new experiences and } \\
\text { achievements }\end{array}$ \\
\hline $\begin{array}{l}\text { Solution- } \\
\text { Focused Ther- } \\
\text { apy (SFT) }\end{array}$ & $\begin{array}{l}\text { Present and future time orienta- } \\
\text { tion; rejects the notion that } \\
\text { "problems" serve ulterior mo- } \\
\text { tives or provide secondary gain; } \\
\text { people contain untapped un- } \\
\text { conscious resources and are } \\
\text { competent to reach their own } \\
\text { goals; language shapes reality }\end{array}$ & $\begin{array}{l}\text { Steer people from "prob- } \\
\text { lem talk" to "solution } \\
\text { talk"; resolve presenting } \\
\text { complaints by helping peo- } \\
\text { ple do or think something } \\
\text { different rather than repeat } \\
\text { past mistakes }\end{array}$ & $\begin{array}{l}\text { Assist people in amplify- } \\
\text { ing exceptions, when the } \\
\text { problem does not occur, } \\
\text { and create effective solu- } \\
\text { tions, of which people are } \\
\text { believed to already possess } \\
\text { the capacity to invoke }\end{array}$ & $\begin{array}{l}\text { The clinician reframes the } \\
\text { problem in a more positive } \\
\text { light that compliments people } \\
\text { on their patient endurance and } \\
\text { resourcefulness; miracle } \\
\text { questions; exception questions; } \\
\text { scaling questions }\end{array}$ \\
\hline
\end{tabular}

ple in self-advocacy and long-term perseverance of recovery in phase three, community reintegration, where individuals and family members endeavor to maintain rehabilitation gains and meet their long-term needs for recovery.

Family therapy is predicated on the belief that the family is an interactive and dynamic system wherein a change in one part of the unit will facilitate change across the system as a whole. Given that brain injury markedly changes the family system, family psychotherapy provides a unique advantage to intervene with the system as a whole as well as meet the needs of individual family members. Similarly, structured family intervention seeks to make systemic change by interceding with the survivor, and at least one family member, in order to provide education, support, and skill-building to available family constituents. Both types of psychological intervention allow for families to receive the necessary support and assistance required to cope with the long-term nature of the brain injury.

\subsection{Recommendations for family systems-based intervention}

Unfortunately, many community settings do not have access to a structured family intervention program or a clinician trained in both family systems intervention and the implications of neurological injury. Furthermore, family psychotherapy and intervention is often performed without a cohesive theoretical framework to guide the assessment, goal-setting, and treatment. Professionals wising to offer a more comprehensive psychotherapy service may wish to utilize a theoretical model to provide cohesive intervention and treatment. Drawing on systemic theoretical models of care, Cognitive Behavioral Therapy (CBT), Narrative Therapy (NT), and Solution Focused Therapy (SFT) are uniquely suited to address the needs of families in community settings postinjury.

\subsection{Cognitive Behavioral Therapy}

Cognitive Behavioral Therapy (CBT) (see Table 1) is a particularly excellent theoretical model as brain injury typically results in physical and cognitive impairments as well as behavioral and emotional difficulties, and CBT integrates cognitive, behavioral, and emotional approaches into treatment. This model presupposes that cognition, behavior, and emotion are interlinked, such that change in one area is thought to produce related change in the other facets of functioning [8]. Empirical evidence suggests that CBT is effective for the treatment of behavioral disorders, deficits in cognition, and emotional disturbances postinjury $[7,31]$. 
CBT relies primarily on psychoeducation, emotional support, and skill building to enhance individual, couple, and family functioning. Specific cognitive interventions include, but are not limited to, identifying and modifying maladaptive thoughts (negative views of the self, environment, and future), negative attributions (explanatory style), unattainable expectations, and unrealistic standards [8]. Cognition-focused interventions might also involve inquiring about the evidence available for a specific belief system, or replacing negative self-talk, the negative things people say to themselves, with more positive and affirming messages. Emotion-focused CBT interventions can include: enhancing empathy through role play, behaving or thinking "as if" a person felt a particular way, identifying emotional blockages, and addressing emotions that may be minimized or avoided. Finally, behaviorfocused interventions may include: shaping, gradually teaching a new behavior through small incremental changes (successive approximations) until the target behavior is reached, contracts, negative and positive reinforcement, skills training, such as communication, goal setting, problem solving, etc., and behavior exchange, exchanging negative behavior for a more positive behavior, such as exchanging cigarettes for carrot sticks.

Case example: Maya and Aaron arrive in your office after Aaron sustained a severe brain injury as a result of a motor vehicle accident (MVA) five months ago. At the time of injury, Aaron was the driver, and received a Glasgow Coma Scale (GCS) of seven. In addition to his brain injury, Aaron also broke a few ribs and his wrist. Maya was riding in the passenger seat at the time of the injury, but other than minor scrapes and bruises, she was unharmed. Police responding to the two-car accident found the other driver to be at fault, hitting Maya and Aaron after running a red light. Aaron's prognosis is good, and his physical, speech, and occupational therapists agree that his dedication to recovery has allowed him to exceed their expectations. His therapists think he can begin working a few hours a day at his previous job, a construction contractor, in the next month or so. However, when Maya and Aaron, arrive in your office, Aaron shares that he is extremely frustrated with the slow pace of his rehabilitation and reports that he "should have been back to work a lot sooner if only he would have worked harder in this therapies." Aaron cites a sports injury he sustained in college where he broke the lower bones in his leg, his tibia and fibula. He states, "Even with two broken bones, I was back out on the field in six weeks. And now just look at me!
It's been five months since our car accident, and I'm still not back to work!" As Aaron discusses his rehabilitation, Maya becomes tearful. When you ask Maya to share where her tears are coming from, she discloses that she believes the accident is her fault. Maya says, "I saw that other car coming across the intersection, and I thought to myself, 'I don't think he's going to stop.' I feel that I could have warned Aaron, but I did nothing, and now we've got all these medical bills and Aaron hasn't been able to get back to work. All I had to do was say something to prevent the accident, and I didn't. I feel this is all my fault."

After gathering assessment data and interviewing Aaron and Maya, you develop a treatment plan using CBT as the guiding theoretical model. First, it seems that Aaron and Maya both need psychoeducation on brain injury in order to better understand the nature of the injury and typical rehabilitation time line. Aaron believes that a "broken brain" is like a broken leg and blames himself for not getting back to work sooner despite his dedication to his rehabilitative therapies. By providing education about brain injury and Aaron's specific injury, you can help adjust Aaron and Maya's expectations and assist them in creating more reasonable standards for Aaron's recovery and return to work. In addition, like many couples and families, Aaron and Maya are experiencing a great deal of financial strain. Aaron was the primary breadwinner, and in addition to the loss of his income, the couple has received a crushing number of medical bills. You decide that in addition to providing education, it will be important to suffuse the therapy sessions with a great deal of empathy for their experience, emotional support, and hope that the future will be brighter. Finally, Maya, in believing that she should have been able to prevent the accident is engaging in a faulty belief system about her perceived efficacy to stop their vehicle from being hit by a speeding car. You realize that the belief system is helping Maya to retain a sense of control over the accident, but at the same time, blaming herself is resulting in unhealthy levels of guilt, shame, and grief. Over the next series of sessions, you plan to inquire about the evidence for Maya's belief that she should have been able to prevent the accident, ask about the role her series of beliefs play in her sense of control of her life, and gently introduce alternate beliefs that will help Maya, overtime, replace her assumptions with more adaptive beliefs about the accident.

\subsection{Narrative Therapy}

Narrative Therapy (NT) presupposes that human lives are lived and understood primarily through the 
expression of stories people tell about themselves [25]. These stories are shaped by the dominant cultural and socioeconomic context in which each person lives. NT is based on the idea that if people are able to change their stories about themselves, they can change their viewpoint, and ultimately, their lives. The psychologist Jerome Bruner [3] suggested that people tell themselves and others a dominant narrative, but within such a narrative, there are always feelings and lived experience that are left out of this story. By acknowledging new facts and experiences that were previously ignored because they did not fit into a person's or family's dominant narrative, personal narratives can be re-authored, moving people from a place of feeling victimized to empowered.

Narrative therapists believe that by externalizing problems, a process of separating a person or family from the problem, as opposed to the problem being intrinsic to their character, people are more free unite against a problem in order to find a solution to the issue. Furthermore, by acknowledging details and elements previously overlooked by the dominant narrative, people can move beyond their problem saturated stories and find "unique outcomes" or times during which the problem did not exist. By acknowledging unique outcomes, people are able to step into a more whole person beyond simple problem-saturated labels such as a "failed" person or a "brain injured" family.

Case example: Jonathan and his father, Daniel, come to your office for therapy subsequent to Jonathan sustaining a brain injury after drag racing under the influence of alcohol. Jonathan is 17 years old, at the time of admission to the hospital, his GCS was a five. After a great deal of rehabilitation, 18 months later, Jonathan still walks with a limp, but no longer needs the help of a cane. Daniel and Jonathan agree that Jonathan's use of alcohol and drugs has been a long-standing problem since he was 13 years of age. They further disclose that, when Jonathan was 12 years old, Daniel learned that Jonathan's mother was having an affair, and when he confronted his wife, she said she planned to leave the family for her lover. Understandably, Jonathan and his father were devastated. After his mother left, Jonathan grades began to drop in school and he quit his travel soccer team. In your session Jonathan shares that, "I just thought I should have been able to make my mom want to stay. When she left, I began to questions everything about myself, and I didn't feel that I was good enough anymore, so I just stopped trying. I thought to myself, "What's the point?"' Jonathan and his father both have a history of depression. While Dan has gone on antidepressant medication, Jonathan never received treatment and used alcohol and drugs to escape his feelings of sadness and inadequacy. Also, Jonathan and his father report of pattern of Jonathan engaging in risk-taking behavior since his mother left the family, culminating in his MVA.

After meeting with Daniel and Jonathan, you create your treatment plan using a NT approach. Over the course of therapy, you plan to Daniel and Jonathan reauthor their personal stories. You'll want to know about the unique outcomes, or the times that Jonathan did not feel worthless or sad since his mother left. You plan to deconstruct Jonathan's destructive beliefs about himself: that he is worthless, inadequate, and not good enough for his mother to stay with the family. Once these beliefs have identified and deconstructed, you plan to help Daniel and Jonathan externalize their problems, or see that worthlessness and sadness are external to them as people, not inherent elements of their character. You plan to reinforce the externalization by asking Daniel and Jonathan how they respond when the feeling for worthlessness shows up in their lives. Using unique outcomes and previously ignored achievements, you plan to help Daniel and Jonathan author new stories that include more positive character traits and do not allow them to claim responsibility for the decisions Jonathan's mother made to leave the family. By helping Jonathan to address his feelings about his mother's departure and author a new story, he is less likely to use drugs and alcohol as coping mechanisms.

\subsection{Solution-Focused Therapy}

Finally, Solution-Focused Therapy (SFT) is perhaps the antithesis to the individual medical model and traditional rehabilitation paradigm [10]. While the medical model is problem-focused and deficit oriented with a clear hierarchy between professionals and patients, SFT is the opposite side of the coin. After a brain injury, families' sense of independence and competence can be shattered, but SFT emphasizes solutions and competences, viewing the patient and family as the driver of the therapy, with the goal of autonomy, and self-reliance [10]. Similar to NT, SFT advocates a shift from focusing on the problem (in NT this is the problem-saturated story) to concentrating on solutions. In fact, change is likely to occur more rapidly when talk of solutions, instead of problems is initiated to therapy [11], and therapy is more likely to be continued to completion when language reflecting solutions is emphasized over language that supports the maintenance 
of problems [6,34]. Essentially, language in therapy shapes the family's reality.

SFT makes a series specific of assumptions about patients and the nature of effective therapy. The brain injury and its resulting problems are so often the primary focus for both survivors and families alike. However, instead of focusing on problems, SFT clinicians want to know about exceptions or times when the problem didn't occur. Also, SFT assumes people know how to conduct themselves behaviorally, and therefore, focuses on making cognitive, rather than behavioral change [29]. Clinicians employing SFT prefer to focus their attention on the present and future, as opposed to the past. One of the mechanisms SFT clinicians use to assist families in moving away from problem-centered language is a series of questions. These include the miracle question, the exception question, and scaling questions. The miracle question is typically posed like this: Suppose that while you are sleeping tonight, a miracle takes place. The miracle is that the problem about which you are talking about today is solved. When you wake up tomorrow what will be different in each of your lives that will indicate this miracle has taken place? SFT clinicians believe that no problem happens all the time. The exception question is meant to elucidate the times when the problem does not happen and is typically stated like this: Share with me a time when you weren't overcome by grief and sadness? How were you able to do that? Who helped you keep grief at bay? How did that instance unfold differently when grief was not a factor? Scaling questions are meant to understand the intensity of the problem, a family's relative confidence in solving the problem, hopefulness about solutions working to solve the problem, and progress in therapy. In SFT clinicians will typically ask families to rate these ideas on a continuum from one to ten.

Case example: Melissa, 29 years old, and her husband, Michael, 31 years of age, attend an initial assessment session together in your office. Michael sustained a spontaneous left cerebellar (the brain's motor cortex) and intraventricular hemorrhage in a parking lot after attending church with Melissa and their two children one Saturday afternoon. At the time, the hemorrhage also affected other areas of his brain such as the Sylvian fissure (a cortical structure implicated in language function). Michael was in a coma for 12 days and required a craniectomy in order to decompress swelling in the brain. At the time of injury, Jaclyn was five years old and Jeremiah was eight years of age. Melissa was also seven months pregnant with their third child, Justin. Michael's medical records do not provide a GCS, but his presenting difficulties are subacute confusion, impulsivity, poor judgment, impaired memory, and problems with balance and ambulation. In your office, Michael is quite docile, but Melissa shares a number of concerns about Michael's difficulties since the injury. Specifically, she has gotten very little sleep since the new baby, Justin was born, and she feels overwhelmed by taking care of three children along with Michael, who she refers to as her "fourth child." Since the injury, Melissa has had to quite her master's program, and she is very concerned about finances, and Michael was the sole provider for the family. Also, Melissa reports that she have never gotten along well with Michael's family, and in particular, says she "despises" his father and step-mother.

After reflecting on your initial meeting with Michael and Melissa, you devise a treatment plan using SFT as a guiding theoretical principle. Drawing on SFT, you are particularly interested in moving Michael and Melissa away from language that dwells on their many problems, and toward solutions to those problems. In particular, you note Melissa's exhaustion and present dearth of social support. One of your initiatives will be to help Melissa find untapped resources for social support, such as her grandmother who lives in her neighborhood and her extended church family. You also decide that, in the future, you will ask Michael and Melissa the exception question in order to better understand when Melissa doesn't feel overwhelmed and frustrated. You plan to use the exceptions you uncover to help Melissa enhance the times when she is able to keep exhaustion and frustration at bay. As you continue in therapy, you can use scaling questions to understand Melissa's subjective emotional experience, belief in their personal competency to solve their problems, and the couple's hope for change over time.

\section{Discussion}

Unfortunately, in light of the recent research literature, very few injury survivors, if any, regardless of the level of injury severity (e.g., mild, moderate, or severe), make a complete recovery. Therefore, brain injury is a life-long injury that requires professional treatment from critical care settings across the continuum to community reintegration. Unfortunately, family needs to cope with the consequences of the brain injury outlast the availability of rehabilitative services. Given that rehabilitation is largely contingent on the willing presence of at least one family member, meeting survivors' 
as well as families' needs over the lifespan of the injury is of critical importance. Moreover, research indicates that family members may actually have greater needs for psychological support as compared to the survivor [11]. These needs can be compounded by the long-term implications of brain injury and tendency of the injury to place strain on the entire family system and reduce family members' ability to access positive coping skills. The research literature has demonstrated that the support of family members is a key component to maximizing survivors' independence and psychosocial adjustment. Yet, paradoxically, family members often sacrifice their own autonomy and needs for social support in order to support the survivor.

Systemic principles and models of treatment have been available in the field of Marriage and Family Therapy (MFT) since the mid-twentieth century [29]. Yet, despite the established theoretical frameworks, empirically validated interventions, and proven assessment tools for the general population, the fields of physical medicine and rehabilitation and neuropsychology have utilized very little from this parallel discipline. While, systemic frameworks (i.e., CBT, NT, and SFT) seem uniquely suited for clinicians in community settings, further research is required to evaluate the utility of the modalities and techniques associated with these three therapies.

\section{References}

[1] Backhaus, S. L., Ibarra, S. L., Klyce, D., Trexler, L. E., \& Malec, J. F. (2010). Brain injury Coping Skills Group: A preventative intervention for patients with brain injury and their caregivers. Archives of Physical Medicine and Rehabilitation, 91, 840-848.

[2] Brooks, D. N. (1984). Cognitive deficits after head injury. In D. N. Brooks (Ed.), Closed head injury: Psychological, social, and family consequences (pp. 148-178). Oxford: Oxford University Press.

[3] Bruner, J. (1990). Acts of meaning. Cambridge, MA: Harvard University Press.

[4] Christensen, T. M., Skaggs, J. L., Kleist, D. M. (1997). Traumatic brain injured families: Therapeutic considerations. The Family Journal: Counseling and Therapy for Couples and Families, 5, 317-324.

[5] Cunningham, J. M., Chan, F., \& Jones, J. (1999). Brain injury rehabilitation: A primer for case managers. In F. Chan, \& M. J. Leahy (eds), Health care and disability case management (pp. 475-526). Lake Zurich, IL: Vocational Consultants Press.

[6] de Shazer, S. (1994). Words were originally magic. New York: Norton.

[7] Doering, B., \& Exner, C. (2011). Combining neuropsychological and cognitive-behavioral approaches for treating psychological sequelae of acquired brain injury. Current Opinion in Psychiatry, 24, 000-000.
[8] Epstein, N. B., \& Baucom, D. H. (2002). Enhanced cognitivebehavior therapy for couples. Washington, DC: American Psychological Association.

[9] Flanagan, D. A. (1998). A retrospective analysis of expressed emotions (EE) and affective distress in a sample of relatives caring for traumatically brain-injured (TBI) family members. British Journal of Clinical Psychology, 37, 431-439.

[10] Gan, C., Family Systems Theory and Solution-Focused Therapy. Toronto Acquired Brain Injury (ABI) Network. Toronto, ON. 22 Sept. 2010.

[11] Gillen, R., Tennen, H., Affleck, G., \& Steinpreis, R. (1998). Distress, depressive symptoms, and depressive disorder among caregivers of patients with brain injury. Journal of Head Trauma and Rehabilitation, 13, 31-43.

[12] Gingerich, W. J., deShazer, S., Weiner-Davis, M. (1988). Constructing change: A research review of interviewing. In E. Lipchik (ed.), Interviewing (pp. 21-33). Rockville, MD: Aspen.

[13] Godwin, E. E., Kreutzer, J. S., Arango-Lasprilla, J. C., \& Lehan, T. J. (2011). Marriage after brain injury: Review, analysis, and research recommendations. Journal of Head Trauma and Rehabilitation, 26, 43-55.

[14] Goldstein, M. (2004). Traumatic brain injury: A silent epidemic. Annals of Neurology, 27, 327-348.

[15] Gottesman, R. F., Komotar, R., \& Hillis, A. E. (2003). Neurologic aspects of traumatic brain injury. International Review of Psychiatry, 15, 302-309.

[16] Harrison-Felix C, Newton C.N., Hall, K. M., \& Kreutzer, J. S. (1996). Descriptive findings from the Traumatic Brain Injury Model Systems National Database. Journal of Head Trauma Rehabilitation, 11, 1-14.

[17] Kreutzer, J. S., Zasler, N. D., Camplair, P. S., \& Leininger, B. E. (1990). A practical guide to family intervention following adult traumatic brain injury. In J. S. Kreutzer and P. Wehman (eds), Community integration following traumatic brain injury (pp. 249-273).

[18] Kreutzer, J. S., Gervasio, A. H., \& Complair, P. S. (1994). Primary caregivers' psychological status and family functioning after traumatic brain injury. Brain Injury, 8, 197-210.

[19] Kreutzer, J. S., Sander, A. M., \& Fernandez, C. C. (1997). Misperceptions, mishaps, and pitfalls in working with families after traumatic brain injury. Journal of Head Trauma Rehabilitation, 12, 63-73.

[20] Kreutzer, J. S., Kolakowsy-Hayner, S. A., Demm, S. A., \& Meade, M. A. (2002). A structured approach to family intervention after brain injury. Journal of Head Trauma and Rehabilitation, 17, 349-367.

[21] Kreutzer, J. S., Stejskal, T. M., Ketchum, J. M., Marwitz, J. H., Taylor, L. A., \& Menzel, J. C. (2009). A preliminary investigation of the brain injury family intervention: Impact on family members. Brain Injury, 23, 535-547.

[22] Langlois, J. A., Rutland-Brown, W., \& Thomas, K. E. (2006). Traumatic brain injury in the United States: Emergency department visits, hospitalizations, and deaths. Atlanta: Centers for Disease Control and Prevention, National Center for Injury Prevention and Control.

[23] Lezak, M. D. (1988). Brain damage is a family affair. Journal of Clinical and Experimental Neuropsychology, 10, 111-123.

[24] Lynch, R. T. (1986). Traumatic brain injury: Implications for rehabilitation counseling. In T. F. Riggar, D. R. Maki, \& A. W. Wolf (eds), Applied rehabilitation counseling (pp.262-270). New York, NY: Springer.

[25] Madigan, S. (2005). Narrative therapy. Baltimore, MD: United Book Press. 
[26] McDaniel, S. H., Hepworth, J., \& Doherty, W. J. (1992). Medical family therapy: A biopsychosocial approach to families with health problems. New York: Basic Books.

[27] Miller, L. (1993). Family therapy of brain injury: Syndromes, strategies, and solutions. The American Journal of Family Therapy, 21, 111-121.

[28] Molloy, M. (1983). New perspectives in cognitive rehabilitation. Australian Rehabilitation Review, 7, 34-37.

[29] Nichols, M. P., \& Schwartz, R. C. (2004). Family therapy concepts and methods. Boston, MA: Pearson Education, Inc.

[30] Polusny, M. A., Kehle, S. M., Nelson, N. W., Erbes, C. R., Arbisi, P. A., \& Thuras, P. (2011). Longitudinal effects of mild traumatic brain injury and posttraumatic stress disorder comorbidity on post-deployment outcomes in National Guard soldiers deployed to Iraq. Arch Gen Psychiatry 68, 79-89.

[31] Ponsford, J. (2004). Cognitive and behavioral rehabilitation: From Neurobiology to clinical practice (the science and practice of neuropsychology). New York, NY: The Guilford Press.

[32] Prigatano, G. P. (1992). Personality disturbances associated with traumatic brain injury. Journal of Consulting and Clinical Psychology, 60, 360-368.

[33] Rutland-Bown, W., Langlois, J. A., Thomas, K. E., Xi, Y. L. (2006). Incidence of Traumatic Brain Injury in the United States, 2003. Journal of Head Trauma Rehabilitation, 21, 544548.

[34] Sheilds, C., Sprenkle, D. H., \& Constantine, J. A. (1991).
Anatomy of an initial interview: The importance of joining and structuring skills. American Journal of Family Therapy, 19, 3-18.

[35] Smith, L. M., \& Godfrey, H. P. D. (1995). Family support programs and rehabilitation: A cognitive-behavioral approach to traumatic brain injury. New York and London: Plenum Press.

[36] Taber, K. H., Warren, D. L., Hurley, R. A., \& Hayman, L. A. (2006). Blast related traumatic brain injury: What is known? Journal of Neuropsychiatry and Clinical Neuroscience, 18, 141-142.

[37] Tate, R. L., Fenelon, B., \& Manning, M. L. (1991). Patterns of neuropsychological Impairment after severe blunt injury. Journal of Nervous and Mental Diseases, 179, 117-126.

[38] Testa, J. A., Malec, J. F., Moessner, A. M., \& Brown, A. W. (2006). Predicting family functioning after TBI. Impact of neurobehavioral factors. Journal of Head Trauma and Rehabilitation, 3, 236-247.

[39] Webster, G., Daisley, A., \& King, N. (1999). Relationship and family breakdown following acquired brain injury: The role of the rehabilitation team. Brain Injury, 13, 593-603.

[40] Zaloshnja, E., Miller, T., Langlois, J. A., \& Selassie, A. W. (2008). Prevalence of long-term disability from Traumatic Brain Injury in the Civilian Population of the United States, 2005. Journal of Head Trauma and Rehabilitation, 23, 394400 . 